\title{
Improved HPLC Method for the Determination of Niflumic Acid in Human Plasma and Its Application to a Bioequivalence Study of Talniflumate Tablets
}

\author{
Eun Ji Park, Y' Young-Hee Shin, Kang Choon Lee, ${ }^{\dagger}$ and Dong Hee Na \\ College of Phamacy, Kinngstmg Lniversity, Busan 608-736, Korea. "E-mail: dha2aks ac.kr \\ ${ }^{\dagger}$ Drig Targeting Laboratory, College of Pharmacy, Sungkwnkwan Lniversity, Sum $4+0-7+6$, Korea \\ Recerved Atrgust 17, 2007
}

Key Words : Niflumic acid. Talniflumate. HPLC. Bioequivalence

Niflunic acid (NFA), 2-( $\alpha . \alpha . \alpha$-trifluoro- $m$-toluidino) nicotinic acid, is a potent analgesic and anti-inflammatory drug. and its prodrug, talnifluntate. 3-phthalidyl ester of 2 ([3-(trifluoromethyl)phenyl|amino)-3-pyridinecarboxylic acid. has been widely used for the treatment of rheumatoid diseases. ${ }^{1}$ Talniflumate, which is synthesized by esterification of the carboxyl group of NFA. exerts its activity in the body through its conversion to NFA by esterase. It has been reported to show lower ulcerogenic side effects and greater anti-inflammatory activity than the NFA. ${ }^{2}$

Several methods for the determination of NFA in biological fluids have been published. including luninescence. ${ }^{3}$ gas chronatography ${ }^{4}$ and high-performance liquid chromatography (HPLC) ${ }^{-i \mathrm{jic}}$ Among them. some sensitive HPLC methods have been applied to bioequivalence study of talniflumate formulations. Recently. Lee et al. reported simple and sensitive HPLC method of NFA in human plasmia for the bioequivalence study of talniflumate tablet. ${ }^{\text {jo }}$ This method used isocratic elution with a mixture of sodium acetate buffer $(\mathrm{pH} 6.4)$ and acetonitrile $(63: 37 . \mathrm{v} / \mathrm{v})$ as a mobile phase and it was validated with a linear concentration range of $0.02-5.0 \mu \mathrm{g} / \mathrm{mL}$. However, it was found that this method did not show enough specificity. As blood samples such as serum or plasma are very complex fluid containing many different conponents. the analy tical method for bioequivalence study should separate the drug from as much of the endogenous material as possible

The purpose of this study was to develop more selective and sensitive HPLC method for the determination of NFA in human plasma and validate it for the bioequivalence study of two talniflumate formulations in healthy male Korean volunteers.

Figure 1 shows the HPLC cluromatograms obtained using method reported previously. ${ }^{1 j}$ which used a mixture of sodium acetate buffer $(\mathrm{pH} \mathrm{6.4)}$ and acetonitrile $(63: 37 . \mathrm{v} / \mathrm{v})$ as a mobile phase. In this condition. the indomethacin used as internal standard (IS) was eluted at a position near endogenous peaks. Therefore, as shown in Figure IB and $\mathrm{IC}$. the interfering endogenous peak observed in the blank plasmia samiple (Figure 1A) was overlapped with the peak of IS. In order to separate IS from endogenous materials. $\mathrm{pH}$ of mobile phase in HPLC was modulated by varying $\mathrm{pH}$ of sodium acetate buffer in the mobile phase (Figure 2). As the $\mathrm{pH}$ of mobile phase was lowered. the elution time of IS peak

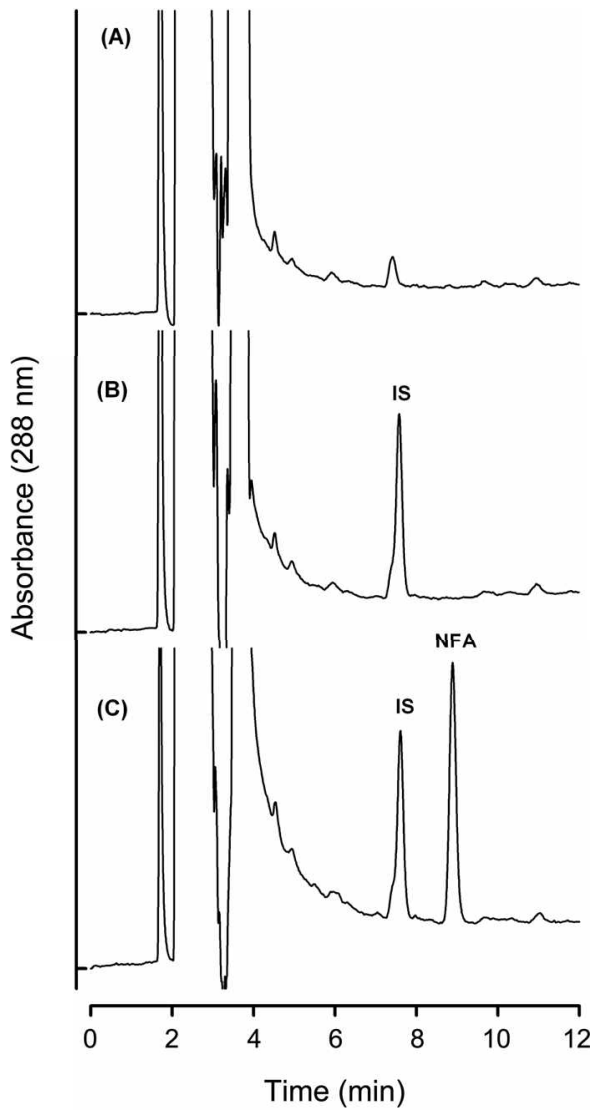

Figure 1. HPLC chromatograms of (A) blank human plasma, (B) plasma spiked with indomethacin as IS and (C) plasma spiked with IS and $0.5 \mathrm{tg} / \mathrm{mL}$ NFA obtained using mobile phase of sodium acetate buffer $(\mathrm{pH} 6.4 ; 0.1 \mathrm{M})$ acetonitrile $(63: 37, \mathrm{v} / \mathrm{v})$ in a flow rate of $1.0 \mathrm{~mL} / \mathrm{min}$, as reported previously. ${ }^{10}$

was delayed. whereas that of NFA peak was relatively constant. The delayed elution time of IS peak may be attributed to the change of polarity of IS (indomethacin). As the $\mathrm{p} K_{\text {at }}$ value of indomethacin is 4.5 . the decrease in $\mathrm{pH}$ value of mobile phase from 6.4 to 5.7 can affect the ratio of ionized/ unionized indomethacin. i.e. the lowered $\mathrm{pH}$ decreases polarity of indomethacin and delays its elution time from reversed-phase column. On the other hand. NFA is fully deprotonated in the range of $\mathrm{pH} 5.7-6.4$ and its polarity is constant. When the sodium acetate buffer at $\mathrm{pH} 6.0$ was used. the two peaks from IS and NFA appeared to be over- 


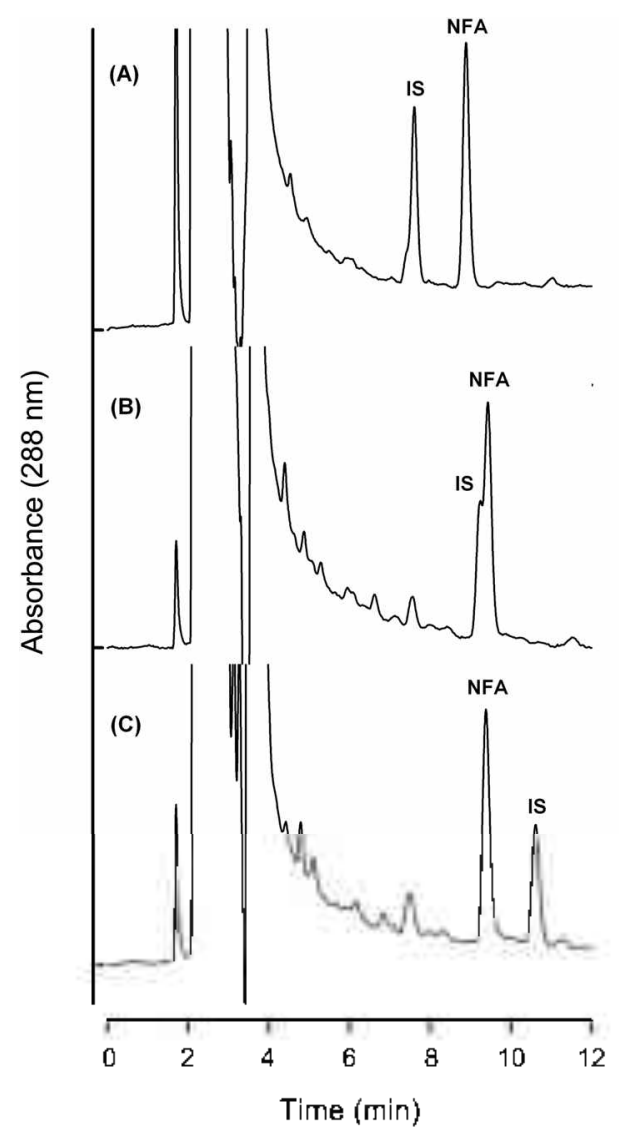

Figure 2. HPLC chromatograms of plasma spiked with IS and 0.5 $\mu \mathrm{g} / 112 \mathrm{~L}$ NFA obtained using mobile phase of (A) sodium acetate buffer ( $\mathrm{pH} 6.4 ; 0.1 \mathrm{M}$ ) acetonitrile $(63: 37, \mathrm{v} / \mathrm{v}),(\mathrm{B})$ sodium acetate buffer $(\mathrm{pH} 6.0 ; 0.1 \mathrm{M})$ :acetonitrile $(63: 37, \mathrm{v} / \mathrm{v})$ and $(\mathrm{C})$ sodium acetate buffer $(\mathrm{pH} 5.7 ; 0.1 \mathrm{M})$ acetonitrile $(63: 37, \mathrm{v} / \mathrm{v})$ in a flow rate of $1.0 \mathrm{~mL} / \mathrm{hnin}$.

lapped each other. With sodium acetate buffer at $\mathrm{pH} 5.7$, IS and NFA peaks could be well separated. At this condition. both IS and NFA peaks could be also separated from interfering peaks present in plasma. Finally. NFA and IS were detected at the retention times of 7.9 and 8.9 min. respectively, in higher flow rate of $1.2 \mathrm{~mL} / \mathrm{min}$ (Figure 3).

In the validation study of the HPLC method the intra- and inter-day accuracies were $92.2-102.6 \%$ and $84.3-101.1 \%$. respectively. and the intra- and inter-day precisions were $0.9-3.5 \%$ and $2.3-6.7 \%$. respectively (Table 1 ). The limit of quantitation (LOQ) of NFA was $0.01 \mu \mathrm{g} / \mathrm{mL}$ (signal-tonoise ratio of 10 ) and the minimum detectable level (LOD) was $0.005 \mu \mathrm{g} / \mathrm{mL}$ (signal-to-noise ratio of 3). The LOQ was lower than those obtained by previous studies. ${ }^{7,9.11}$ The calibration curve for NFA showed a good linear relationship over the concentration range of $0.01-2.0 \mu \mathrm{g} / \mathrm{mLL}$ in human plasma with $\hat{r}^{\hat{}}=0.999$. The slope and intercept were 4.38 and 0.0008 , respectively.

The validated HPLC method was applied to a bioequivalence study of two talniflumate tablets. Bioequivalence study is performed to assess the biological equivalence of two products of the same drug. Two phamaceutical products are bioequivalent if they are pharmaceutically equi-

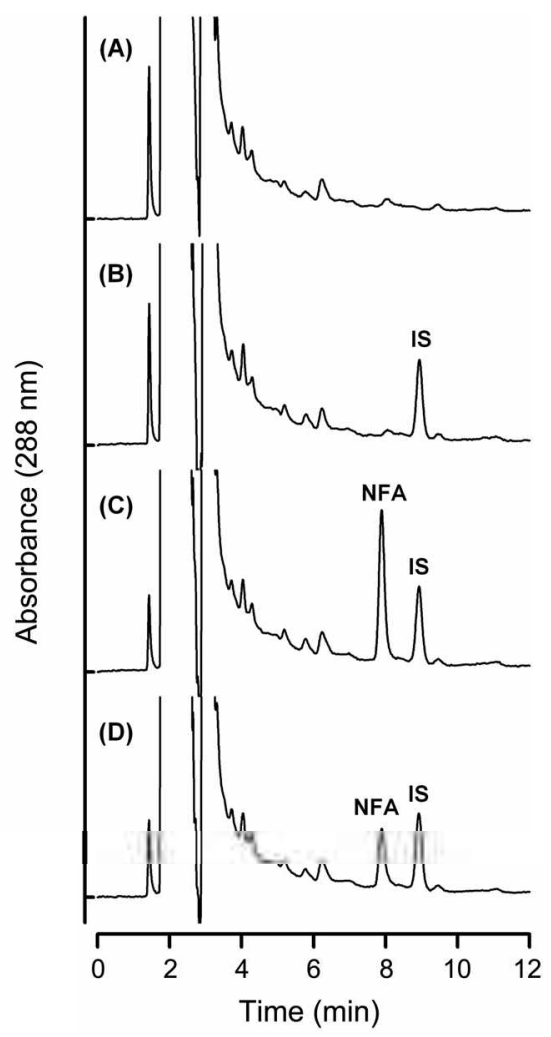

Figure 3. HPLC chromatograms of (A) blank human plasma, (B) plasma spiked with IS, (C) plasma spiked with IS and $0.5 \mu \mathrm{g} / \mathrm{mL}$ NFA, and (D) plasma from a volunteer at $2 \mathrm{~h}$ after the oral administration of Somalgen tablet $(370 \mathrm{mg}$ ) obtained with mobile phase of sodium acetate buffer ( $\mathrm{pH} 5.7 ; 0.1 \mathrm{M}$ ):acetonitrile $(63: 37$, $\mathrm{v} / \mathrm{v}$ ) in a flow rate of $1.2 \mathrm{~mL} / \mathrm{min}$.

Table 1. Precision and accuracy of the HPLC method for the determination of NFA in human plasma

\begin{tabular}{cccccc}
\hline \multirow{2}{*}{$\begin{array}{c}\text { Concentration } \\
(t g / \mathrm{mL})\end{array}$} & \multicolumn{2}{c}{ Precision (\%) } & & \multicolumn{2}{c}{ Accuracy (\%) } \\
\cline { 2 - 3 } \cline { 5 - 6 } & Intra-day & Inter-day & & Intra-day & Inter-day \\
\hline 0.01 & 2.16 & 6.66 & & 92.18 & 84.28 \\
0.02 & 3.47 & 3.01 & & 96.28 & 93.07 \\
0.05 & 2.91 & 2.82 & & 102.20 & 97.87 \\
0.20 & 1.10 & 4.74 & & 93.10 & 99.43 \\
0.50 & 0.86 & 2.40 & & 102.63 & 101.12 \\
1.00 & 1.20 & 3.01 & & 101.53 & 100.24 \\
2.00 & 1.71 & 2.28 & & 101.87 & 99.92 \\
\hline
\end{tabular}

valent and their bioavailabilities after administration in the same dose are not significantly different. The United States Food and Drug Administration (FDA) has defined bioequivalence as the absence of a significant difference in the rate and extent to which the active ingredient or active moiety in pharmaceutical equivalents or phamaceutical alternatives becomes available at the site of drug action when administered at the same molar dose under similar conditions in an appropriately designed study. "Figure 4 represents the mean $( \pm$ S.D. plasma concentration-time profiles of NFA after administration of a single oral dose $\left(370 \mathrm{mg}\right.$ ) of two talniflumate tablets. TALIFUL ${ }^{\text {sablets }}$ (test 


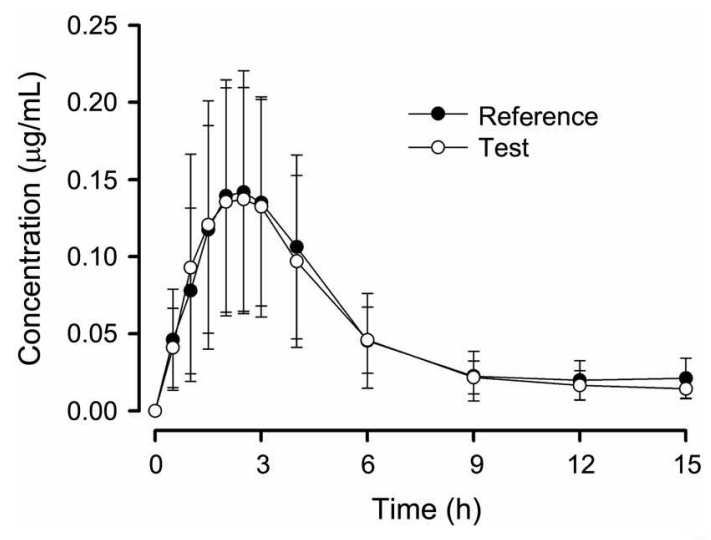

Figure 4. Mean plasna concentration-time curves of NFA tollowing the oral administration of reference and test fonmulations at a dose of $370 \mathrm{mg}$ of talniflumate to human subjects (mean \pm S.D., n $=24$ ).

medication) from Kwang-Dong Pharmaceutical Co. Ltd. (Seoul. Korea) and SOMALGEN ${ }^{\circledR}$ tablets (reference medication) from Kun-Wha Pharnaceutical Co. Ltd. (Seoul. Korea). The phammacokinetic parameters were listed in Table 2. The bioequivalence of two products of the same drug implies their equivalence with respect to the rate and extent of drug absorption. While the area under the plasma concentration versus time curve (AUC) generally serves as the characteristic of the extent of drug absorption. the maximum plasma concentration $\left(\mathrm{C}_{\mathrm{mak}}\right)$ and time point of maxinum plasma concentration $\left(\mathrm{T}_{\text {nilax }}\right)$ reflect the rate of drug absorption. The regulatory limits are that the $90 \%$ confidence intervals for the ratios (testreference) of the AUC ratio and $\mathrm{C}_{\text {maks }}$ ratio must fall between $80 \%$ and $125 \%{ }^{11}$ The parametric point estimates for the mean of the test medication/the mean of the reference medication for $\mathrm{AUC}_{C_{1-t}}$ and $\mathrm{C}_{\max }$ were $1.012 \%$ and $1.007 \%$. respectively. and the parametric $90 \%$ confidence intervals for $\mathrm{AUC}_{i,-1}$ and $\mathrm{C}_{\text {milax }}$ were $0.8774<\delta<1.2232$ and $0.8482<\delta<1.1919$. respectively' which were within the accepted range of $0.80-1.25 \mathrm{by}$ the Korean Food and Dnug Administration. As shown in Table 2. the pharmacokinetic parameters. such as $\mathrm{AUC}_{\mathrm{ij-t} .}$. $A U C_{x}, t_{1: s}, C_{\text {max }}$ and $T_{\max }$ of the test drug were similar to those of the reference drug. This result indicates that the bioavailabilities between SOMALGEN (reference drug) and TALIFUL (test drug) tablets were not significantly different.

In conclusion, the HPLC method for the determination of

Table 2. Phamacokinetic parameters for each volunteer obtained after oral administration of SOMALGEN ${ }^{2}$ and TALIFUL tablets at the talniflumate dose of $370 \mathrm{mg}$

\begin{tabular}{lcc}
\hline $\begin{array}{l}\text { Pharmacokinetic } \\
\text { parameters }\end{array}$ & $\begin{array}{c}\text { SOMALGEN } \\
\text { (mean } \pm \text { S.D. }\end{array}$ & $\begin{array}{c}\text { TALIFUL } \\
\text { (mean } \pm \text { S.D. }\end{array}$ \\
\hline $\mathrm{T}_{\text {max }}(\mathrm{h})$ & $2.54 \pm 0.83$ & $2.35 \pm 0.76$ \\
$\mathrm{C}_{\text {max }}(\mu \mathrm{g} / \mathrm{mL})$ & $0.16 \pm 0.07$ & $0.16 \pm 0.08$ \\
$\mathrm{AUC}_{0 . \mathrm{t}}(\mu \mathrm{g} \mathrm{h} / \mathrm{mL})$ & $0.66 \pm 0.36$ & $0.67 \pm 0.33$ \\
$\mathrm{AUC}_{\times}(\mu \mathrm{g} \mathrm{g} / \mathrm{hL})$ & $0.69 \pm 0.42$ & $0.71 \pm 0.37$ \\
$\mathrm{t}_{\mathrm{l}: 2}(\mathrm{~h})$ & $2.37 \pm 1.10$ & $2.77 \pm 1.38$ \\
\hline
\end{tabular}

NFA in human plasma was improved in terns of sensitivity and selectivity and successfully validated. The improved HPLC method was applicable to bioequivalence study of talniflumate tablets ( $370 \mathrm{mg}$ oral dose) in human volunteers. This method would be also useful for other bioavailability and clinical studies of talniflumate formulations.

\section{Experimental Section}

Materials and reagents. NFA and indomethacin were purchased from Sigma (St. Louise. MO. USA). Methanol, acetonitrile and acetic acid in HPLC grade were obtained by J. T. Baker (Plilipsburg. NJ. USA). Somalgen tablets (talniflumate $370 \mathrm{mg}$ ) were obtained from Kur-Wha Pharm. Co. Ltd. (Seoul. Korea). Taliful tablets (talniflumate $370 \mathrm{mg}$ ) were supplied from Kwang-Dong Pharm. Co. Ltd. (Seoul, Korea). All other chemicals were of analytical grade and were obtained commercially

Preparation of standard solutions. Stock solution of NFA ( $1 \mathrm{mg} / \mathrm{mL}$ ) was prepared in methanol and dissolved in human plasma to obtain a concentration of $0.01,0.02 .0 .05$, $0.2,0.5,1$ and $2 \mu \mathrm{g} / \mathrm{mL}$. Stock solution of internal standard (IS), indomethacin, was diluted with methanol to a funal concentration of $10 \mu \mathrm{g} / \mathrm{mL}$. All solutions were stored in a freezer at $-70^{\circ} \mathrm{C}$ until analysis.

Preparation of plasma samples. A volume of $50 \mu \mathrm{L}$ of indomethacin $(10 \mu \mathrm{g} / \mathrm{mL})$ was spiked into $0.5 \mathrm{~mL}$ of human plasma. To remove protein in human plasma, $0.9 \mathrm{~mL}$ of methanol was added to the mixture. After vortex mixing for $60 \mathrm{sec}$ and centrifugation at $5000 \mathrm{rpm}$ for $30 \mathrm{~min}$ at $4{ }^{\circ} \mathrm{C}$. $100 \mu \mathrm{L}$ of supenatant was directly injected into the HPLC system.

Chromatographic conditions. Chromatography was performed using a Dionex HPLC system (Dionex Co.. Gemering. Germany) consisted of a quaternary gradient pump with an on-line vacuum degasser (Model P680 A). an automated sample injector (Model ASI-100), thermostatted column compartment (Model TCC-100) and 4-channel multi UVVis detector (Model 170U). Separations were carried out on a Gemini C18 column $(4.6 \times 250 \mathrm{~mm} .5 \mu \mathrm{m}$. Phenomenex, CA. USA) at $25^{\circ} \mathrm{C}$. The samples were separated by isocratic elution with the mobile phase prepared by mixing $0.1 \mathrm{M}$ sodium acetate buffer $(\mathrm{pH} 5.7,5.8,6.0,6.2$ or 6.4 adjusted with acetic acid) with acetonitrile at a ratio of $63: 37(\mathrm{v} / \mathrm{v})$. The flow rate was 1.0 or $1.2 \mathrm{~mL} / \mathrm{min}$ and UV absorbance was monitored at $288 \mathrm{~nm}$.

Method validation. A calibration curve was constructed with blank human plasma and eight NFA standards $(0.0 .01$. $0.02,0.05,0.2,0.5 .1$ and $2 \mu \mathrm{g} / \mathrm{mL}$ ). The linearity of the calibration curve was confirmed by plotting the peak area ratios of NFA to IS versus the NFA concentrations with least-square linear regression analy'sis. The intra- and interday precision and accuracy of the analytical method were determined by analyzing plasma samples at concentration ranges of $0.01-2.0 \mu \mathrm{g} / \mathrm{mL}$. Accuracy was expressed as the mean percentage of analyte recovered in the assay. Intra-day precision was determined by repeated analysis of each 
sample on $I$ day $(n=5)$. Inter-day precision was determined by repeated analysis on five consecutive days $(n=5)$. The concentration of each sample was deternined by using calibration standards prepared on the same day. The limits of detection (LOD) and quantitation (LOQ) were defined as the minimum concentration at the signal-to-noise ratio $(\mathrm{S} / \mathrm{N})=3$ and 10 . respectively.

Bioequivalence test of talniflumate. The bioequivalence study was performed by the approval of the Korean Food and Drug Administration. All of the participants signed a written consent form after they had been informed of the nature and details of the study in accordance with the Korean Guidelines for Bioequivalence Test. Twenty-four healthy male Korean volunteers with an average age of 26.1 years and an average weight of $72.2 \mathrm{~kg}$ were selected for this study after passing a clinical screening procedure including hematology. biochemistry, electrolytes and urine analysis. Each volunteer received a single dose of one talniflumate tablet $(370 \mathrm{mg})$ in a standard $2 \times 2$ cross-over model in a randomized order. There was 14 days washout period between the doses. The subjects were hospitalized (Dong-A University Hospital, Busan. Korea) at 6:00 p.m.. the day before each drug administration. After 7:00 a.m., the median cubital vein was cannulated and $1 \mathrm{~mL}$ of heparinized injectable normal saline solution was flushed into the cannula to prevent blood clotting. The doses were taken at $8.00 \mathrm{a} . \mathrm{m}$. of each dosing day along with $240 \mathrm{~mL}$ of tap water. At $4 \mathrm{~h}$ after the oral administration. all of the subjects were given standardized meals. The subjects were not allowed to rentain in the supine position or to sleep until $8 \mathrm{~h}$ after the oral administration. Approxinately $5 \mathrm{~mL}$ of blood samples were collected via the cannula at the following times; pre-dose. $0.5 .1,1.5 .2,2.5 .3 .4,6,9.12$ and $15 \mathrm{~h}$ after the administration. The plasma samples were separated by centrifugation at $3000 \mathrm{rpm}$ for $10 \mathrm{~min}$ and stored at $-70{ }^{\circ} \mathrm{C}$ until the HPLC analy sis.

The pharmacokinetic parameters including maximum plasma concentration $\left(\mathrm{C}_{\mathrm{max}}\right)$. time point of maximum plasma concentration $\left(\mathrm{T}_{\text {nax }}\right)$, area under the plasma concentration versus time curve from $0 \mathrm{~h}$ to the last measurable concentration (AUC $((-1))$, area under the plasma concentration versus time curve from $0 \mathrm{~h}$ to infinity (AUC) and half-life of drug elimination during the terminal phase $\left(\mathrm{t}_{1: 2}\right)$ were determined with the K-BE Test 2002 supplied by the Korean Food and Drug Administration (Seoul, Korea).

\section{References}

1. Insel. P. A. In The Pharnacological Basis of Therapeutics; Hardmant. J. G.: Limbird. L. E.. Eds.: McGraw-Hill: New York. U.S.A., 1996: p 617.

2. Los. M.: Bonded, J. E.; Piccinali. C. Farmaco. 1981. 36. 372.

3. Egorova, A.: Beltyukova, S.: Teslyuk, O.: Karpinchik, V. J. Pharn. Bioned Anal 2001. 24. 1081 .

4. Houin. G.: Bree. F.: Tillement. J. P. J. Chomatogr: 1981. 223.351.

5. Guechot. C.: Nicolle. P. J. Chronatogr: 1984. 303.440.

6. Avgerinos. A.; Malamataris, S. J. Chromatogr: 1990, 553. 271.

7. Kim. H. J.: Han. Y. H.: Chung, S. J; Lee, M. H.; Shim, C. K Arch Pham Res. 1996, 19.297.

8. Gowik. P.: Tulicher. B.: Uhlig. S. J. Chrontatogr: B 1998. 716. 221.

9. Jang. D. J.: Park. J. S.: Ko. H. R.: Tee. J. P.: Kim. J. K.: Kim. S. T.: Kim. C. K. Biomed Chromatog: 2005. 19, 32

10. Lee. H. W: Won. K. J.: Cho. S. H. Ha. Y. H.: Park. W. S.: Ym, H T.: Baek. M.; Rew. J. H.: Yoon. S. H.: Ym, S. V.: Chung. J. H: Lee. K. T. J. Chrontatogr B 2002. 821. 215.

11. FDA Guidance for Industr: Biomailability and Bioequivalence Studies for Orally Adnthistered Dnty Products-General Constderations: US Department of Health and Human Services. Food and Drug Administration, Center for Drug Evaluation and Research (CDER); 2003. Website: httplinww.fda.govicder: guidance:index:htm. 